\title{
A PSICOMOTRICIDADE: UMA FERRAMENTA DE AJUDA AOS PROFESSORES NA APRENDIZAGEM ESCOLAR
}

\author{
Patricia Baldecera Xisto', Luciana Borba Benetti² \\ ${ }^{1}$ Pós-Graduada do Curso de Especialização em Educação: Interdisciplinaridade e Transversalidade, Campus São \\ Gabriel, Unipampa. \\ xistopatricia@bol.com.br \\ ${ }^{2}$ Professora Adjunta da Universidade Federal do Pampa, Campus São Gabriel. \\ lucianabenetti@unipampa.edu.br
}

\section{RESUMO}

Esta pesquisa tem como objetivo primordial constatar a importância que a psicomotricidade se bem trabalhada com exercícios motores desenvolvidos em quadra e em sala de aula podem desenvolver uma melhora significativa. Sabe-se que a psicomotricidade se caracteriza por uma educação que se utiliza do movimento para atingir outras aquisições mais elaboradas como intelectuais. As entrevistas foram direcionadas a professores das séries iniciais de uma escola municipal de ensino fundamental e serviram para ouvir o que os professores tem a dizer sobre a importância dessa ferramenta de ajuda para a aprendizagem.

Palavras-Chave: Educação, Psicomotricidade, Aprendizagem

\begin{abstract}
This research aims to establish the primary importance that is well crafted with psychomotor exercises engines developed in court and in the classroom can develop a significant improvement in learning. It is known that is characterized by psychomotor education that the movement is used to achieve other more elaborate and intellectual acquisitions. The interviews were aimed at teachers of early grades of a public school and high school used to listen to what teachers have to say about the importance of this tool to help learning.
\end{abstract}

Keywords: Education, Psychomotricity, Learning

\section{INTRODUÇÃO}

Santos et al(2009) se refere que a psicomotricidade nada mais é que se relacionar através da ação, como um meio de tomada de consciência que une o corpo, a mente, a sociedade e está associada à afetividade e à personalidade, porque o indivíduo utiliza seu corpo para demonstrar o que sente.

Vitor da Fonseca (1988) comenta que a psicomotricidade é atualmente concebida como a integração superior da motricidade, produto de uma relação inteligível entre a criança e o meio.

Santos et al (2009) diz que a consciência do seu corpo e das possibilidades de se expressar por meio desse corpo, localizando-se no tempo e no espaço. É necessário que toda criança passe 
por todas as etapas em seu desenvolvimento. O trabalho da educação psicomotora deve prever a formação de base indispensável em seu desenvolvimento motor, afetivo e psicológico, dando oportunidade para que por meio de jogos, de atividades lúdicas, se conscientize sobre seu corpo.

Para Santos et al, (2009 )"Os aspectos psicomotores: organização espacial, lateralidade, esquema corporal, são fatores importantes no processo de aprendizagem e desenvolvimento da criança. É na fase escolar que as crianças constroem com base no seu esquema corporal a sua estruturação e orientação no espaço e no tempo, são fatores relevantes no processo de aprendizagem e desenvolvimento da criança, pois enriquecem as suas possibilidades de desenvolvimento no que se refere à apropriação de conceitos e formas diferenciadas de pensar, por meio de experiências".

Segundo Barreto (2000), "O desenvolvimento psicomotor é de suma importância na prevenção de problemas da aprendizagem e na reeducação do tônus, da postura, da direcionalidade, da lateralidade e do ritmo".

Para Oliveira (1997), "A educação psicomotora para ser trabalhada necessita que sejam utilizadas as funções motoras perceptivas, afetivas e sócio-motoras, pois assim a criança explora o ambiente, passa por experiências concretas indispensáveis ao desenvolvimento intelectual e é capaz de tomar consciência de si mesma e do mundo que a cerca".

Wallon (2010) afirma que é "sempre a ação motriz que regula o aparecimento e o desenvolvimento das formações mentais". E ainda salienta a importância do aspecto afetivo como anterior a qualquer tipo de comportamento. Existe para ele uma evolução tônica e corporal chamada diálogo corporal e que constitui "o prelúdio da comunicação verbal".

$\mathrm{Na}$ evolução da criança, portanto, estão relacionadas: a motricidade, a afetividade e a inteligência.

Ajuriaguerra (1980), p.211 afirma ser um erro estudar a psicomotricidade apenas sob o plano motor, dedicando-se (...) exclusivamente ao estudo de um "homem motor". Isto conduziria a considerar a motricidade como uma simples função instrumental de valor puramente efetuador e dependente da mobilização de sistemas por uma força estranha a eles, quer seja exterior ou interior ao indivíduo, despersonalizando, assim, completamente a função motora. Ele faz uma comparação entre a evolução da criança e a evolução da sensório-motricidade (op.cit.,p.210):

É pela motricidade e pela visão que a criança descobre o mundo dos objetos e é manipulando-os que ela redescobre o mundo, porém, esta descoberta a partir dos objetos só será verdadeiramente frutífera quando a criança for capaz de segurar e de largar, quando ela tiver adquirido a noção de distância entre ela e o objeto não fizer mais parte de sua simples atividade corporal indiferenciada.

Sabe-se que a psicomotricidade tem papel importante na contribuição para a aprendizagem de crianças em idade escolar. Para atingir esse objetivo a psicomotricidade trabalha na prevenção de problemas de dificuldades escolares tais como: afetividade, leitura e escrita, matemática, atenção, lateralidade, dominância lateral, funções cognitivas, socialização e trabalho em grupo.

Sobretudo a busca por ferramentas de auxílio na aprendizagem escolar tem se tornado multidisciplinar, na qual a Educação Física tem papel importante neste processo.

Propõe-se aqui uma pesquisa de campo que objetiva investigar a visão que os professores possuem da importância da psicomotricidade dentro do contexto ensino-aprendizagem. Foi 
escolhido para esta pesquisa professores de séries iniciais de uma escola municipal do município de São Gabriel.

\section{PSICOMOTRICIDADE : CONCEITO}

Para Oliveira (1997) "A psicomotricidade é um caminho, é o desejo de fazer, de querer fazer, o saber fazer e o poder fazer".

O francês Jean Le Boulch (1983), um dos precursores da utilização da educação psicomotora nas aulas de educação física afirma que a corrente educativa da psicomotricidade surgiu na França, em 1966, pela fragilidade da educação física, pelo fato dos professores de educação física não conseguirem desenvolver uma educação integral do corpo. Para ele, muitos desses professores centravam sua prática pedagógica nos fatores ligados à execução dos movimentos, tendo como principal objetivo de sua ação educativa chegar à perfeição desses movimentos, de forma mecânica.

A psicomotricidade de Le Boulch (1983) justifica sua ação pedagógica colocando em evidência a prevenção das dificuldades pedagógicas, dando importância a uma educação do corpo que busque um desenvolvimento total da pessoa, tendo como principal papel na escola preparar seus educandos para a vida, utilizando métodos pedagógicos renovados, procurando ajudar a criança a se desenvolver da maneira possível, contribuindo dessa forma para uma boa formação da vida social.

Segundo Meur et al(1984) a psicomotricidade é a posição global do sujeito. Pode ser entendido como a função de ser humano que sintetiza psiquismo e motricidade com o propósito de permitir ao indivíduo adaptar de maneira flexível e harmoniosa ao meio que o cerca. Pode ser entendido como um olhar globalizado que percebe a relação entre a motricidade e o psiquismo como entre o indivíduo global e o mundo externo. Pode ser entendido como uma técnica cuja organização de atividades possibilite à pessoa conhecer de uma maneira concreta seu ser e seu ambiente de imediato para atuar de maneira adaptada.

O termo psicomotricidade apareceu pela primeira vez com Dupré em 1920, significando um entrelaçamento entre o movimento e o pensamento. Desde 1909, ele já chamava a atenção de seus alunos sobre o equilíbrio motor, denominando o quadro de "debilidade motriz". Verificou também que existia uma estreita relação entre anomalias psicológicas e as anomalias motrizes, o que o levou a formular o termo psicomotricidade.

Fonseca (1988) diz que a psicomotricidade atualmente é concebida como a integração superior da motricidade, produto de uma relação entre indivíduo e meio, na qual a consciência se forma e se materializa.

Ainda Fonseca (1988) vê o movimento como realização intencional, como expressão da personalidade e que, portanto, deve ser observado não tanto por aquilo que se vê e se executa, mas também por aquilo que representa e origina.

Segundo Oliveira (1997) "A educação psicomotora deve ser uma formação de base indispensável a toda criança. Ela é um meio de auxiliar a criança a superar suas dificuldades e prevenir possíveis inadaptações. $O$ indivíduo se constrói paulatinamente, através da interação com o meio e de suas próprias realizações e a psicomotricidade desempenha aí um papel fundamental. A educação psicomotora pode ser vista como preventiva e reeducativa na medida em que dá condições à criança de se desenvolver em seu ambiente". 


\section{PSICOMOTRICIDADE: DESENVOLVIMENTO}

\section{Coordenação Global, fina e óculo-manual}

Segundo Oliveira (1997) para uma pessoa manipular os objetos da cultura em que vive, precisa ter certas habilidades que são essenciais. Ela precisa saber se movimentar no espaço com desenvoltura, habilidade e equilíbrio, e ter o domínio do gesto e do instrumento (coordenação fina).

\section{Coordenação Global}

Oliveira (1997) diz que a coordenação global depende da capacidade de equilíbrio postural do indivíduo. Este equilíbrio está subordinado às sensações proprioceptivas cinestésicas e labirínticas. Diversas atividades levam à conscientização global do corpo, como andar, que é um ato neuromuscular que requer, além destes, resistência e força muscular e outras como saltar, rolar, pular, arrastar-se, nadar, lançar, pegar e sentar.

\section{Coordenação fina e óculo-manual}

Para Oliveira (1997) a coordenação fina diz respeito à habilidade e destreza manual e constitui um aspecto particular da coordenação global.

Para Ajuriaguerra 1984(apud Condemarin e Chad Wick,1987),o desenvolvimento da escrita depende de diversos fatores: maturação geral do sistema nervoso, desenvolvimento psicomotor geral em relação à tonicidade e coordenação dos movimentos e desenvolvimento da motricidade finas dos dedos da mão.

\section{Esquema corporal}

Conforme Oliveira (1997) o corpo é uma forma de expressão da individualidade. A criança percebe-se e percebe as coisas que a cercam em função de seu próprio corpo. Isto significa que conhecendo-o, terá maior habilidade para se diferenciar, para sentir diferenças. Ela passa a distingui-lo em relação aos objetos circundantes, observando-os, manejando-os.

Ainda Oliveira (1997) diz que o desenvolvimento do esquema corporal se organiza pela experienciação do corpo da criança. A criança nasce com uma bagagem de sensações e percepções proprioceptivas, mas por falta de mielinização das fibras nervosas, não consegue organizá-la. Oliveira (1997) afirma que a imagem especular trata-se da descoberta pela criança de sua imagem no espelho, o que se dá por volta de seis meses de idade.

Para Lacan, a identificação da criança no espelho constitui uma alienação inicial pelo fato de ela se identificar com uma imagem e não consigo mesma, mas isto também lhe permite um acesso ao mundo da linguagem, facilitando assim que se realize a função do eu. 
Wallon contrasta com as idéias de Lacan de um corpo fragmentado que se reuniria no espelho. Para Wallon, a imagem do corpo se constrói progressivamente por um processo de amadurecimento neurofisiológico da criança.

\section{Etapas do esquema corporal}

Segundo Oliveira (1997) existem 3 etapas do esquema corporal:

- 1a etapa: corpo vivido (até 3 anos de idade) .Esta etapa corresponde à fase da inteligência sensório-motora de Jean Piaget.

- 2a etapa: corpo percebido ou "descoberto" (3 a 7 anos).Esta etapa corresponde à organização do esquema corporal devido à maturação da "função de interiorização" aquisição esta de suma importância porque auxilia a criança a desenvolver uma percepção centrada em seu próprio corpo.

- 3a etapa: corpo representado (7 a 12 anos). No início desta fase a representação mental da imagem do corpo consiste numa simples imagem reprodutora. É uma imagem de corpo estática e é feita da associação estreita entre dados visuais e cinestésicos.

\section{Perturbações do esquema corporal}

Conforme Oliveira (1997), existem algumas crianças que não tem consciência de seu próprio corpo. Podem experimentar algumas dificuldades como, por exemplo, insuficiência de percepção ou de controle de seu corpo, incapacidade de controle respiratório, dificuldades de equilíbrio e de coordenação.

\section{Lateralidade}

Oliveira (1997) comenta que a lateralidade é a propensão que o ser humano possui de utilizar preferencialmente mais um lado do corpo do que o outro em três níveis: mão, olho e pé.

Isto significa que existe um predomínio motor, ou melhor, uma dominância de um dos lados. O lado dominante apresenta maior força muscular, mais precisão e mais rapidez.

\section{Estruturação espacial}

Oliveira (1997) fala que é através do espaço e das relações espaciais que nos situamos no meio em que vivemos em que estabelecemos relações entre as coisas em que fazemos observações comparando-as, combinando-as, vendo as semelhanças e diferenças entre elas.

\section{Estruturação temporal}


Segundo Oliveira (1997) as noções de corpo, espaço e tempo têm que estar intimamente ligadas se quisermos entender o movimento humano. O corpo coordena-se, movimenta-se continuamente dentro de um espaço determinado em função do tempo, em relação a um sistema de referência.

\section{Sistema nervoso}

Segundo Oliveira (1997). O Sistema nervoso é o meio pelo qual o corpo percebe os eventos e lhes responde nos ambientes interno e externo é ele também que coordena e controla todas as atividades do organismo, desde as contrações musculares, o funcionamento de órgãos e até mesmo a velocidade de secreção das glândulas endócrinas. Um indivíduo adulto possui aproximadamente cem bilhões de neurônios. O córtex cerebral é o centro onde são avaliadas as informações e são processadas as instruções ao organismo.

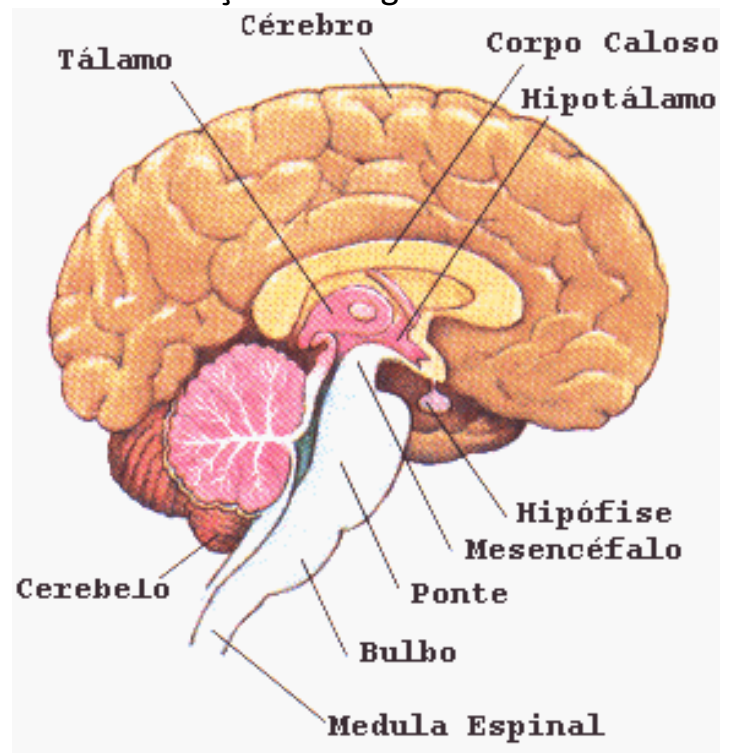

Figura 1: Sistema Nervoso (www.jornalcontraocancer.blogspot.com)

Scott et al(2000) menciona que receptores são capazes de detectar o toque, a dor, a temperatura e os estímulos químicos enviam informações ao Sistema Nervoso Central (SNC) sobre as alterações do ambiente. O SNC responde tanto por meio de movimentos voluntários quanto a uma alteração da taxa de liberação de algum hormônio do sistema endócrino dependendo de qual resposta é apropriada. A condução dos impulsos advindos desses receptores dos centros nervosos se faz através de fibras nervosas sensitivas ou aferentes e a transmissão aos músculos do comando dos centros nervosos é efetuada pelas fibras eferentes ou motoras.

Ainda Scott et al (2000)afirma que "A velocidade dos impulsos nervosos se faz através do revestimento da bainha de mielina encontrada nas fibras nervosas e que é composta por colesterol, fosfatídeos e açucares. Esta bainha possui a função não só de condução como também de isolante e desempenha um papel importante na transmissão de informações. Existe maior 
velocidade nas fibras mielínicas do que nas amielínicas. Quanto mais estimularmos uma criança, mais provocamos nela reações e respostas que se traduzem em número maior de sinapses".

Scott et al (2000) também diz que "A sinapse é uma conexão entre os neurônios na qual um neurônio estimula o seguinte através da liberação do neurotransmissor, propagando-se assim os impulsos nervosos e transmitindo as informações".

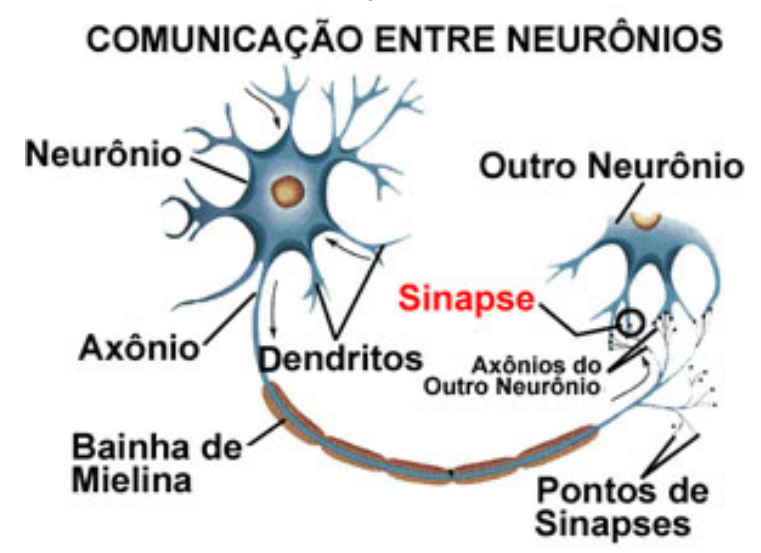

Figura 2: Sinapse (www.psiqweb.med.br)

Para Scott et al(2000) existem algumas funções do sistema nervoso no que se relaciona aos movimentos:

- Movimento Voluntário: Ele depende de nossa vontade, há uma representação mental do movimento, uma intenção e a execução do movimento.

- Movimento Reflexo: É independente de nossa vontade. O estímulo é captado pelos receptores sensoriais do organismo e levado ao centro nervoso e de lá provoca imediatamente a resposta motora.

- Movimento Automático: Depende normalmente da aprendizagem, do treino, da prática e da repetição.

\section{A interligação entre psicomotricidade e aprendizagem}

De acordo com Oliveira (1997), o saber ler e escrever se tornou uma capacidade indispensável para que o indivíduo se adapte e se integre ao meio social. Sendo sua leitura e a escrita manifestações de linguagem importantes para essa integração com o ambiente.

Para Oliveira (1997) é utilizado por muitos professores a repetição constante de exercícios. Neste sentido, uma crítica faz-se necessária: numa tentativa desenvolver a motricidade de seus alunos, os manda preencher folhas e mais folhas de riscos à direita, à esquerda, verticais, horizontais, bolinhas, ondas. Inequivocadamente acreditam que a criança assimila estes termos e passam para outros itens que serão treinados "da mesma maneira, pois estes exercícios são desprovidos de significado para as crianças e não são nem precedidos de um trabalho mais amplo de conscientização de movimentos, de posturas, visando a um desenvolvimento mental maior". Um fator importante que a criança se movimenta em um determinado espaço e tempo. Uma boa orientação espacial poderá capacitá-la a orientar-se no meio com desenvoltura.

Foi na obra de Henry Wallon, onde se buscou posicionamento para a noção básica de unidade funcional e biológica da pessoa, na qual o psiquismo e a motricidade representam e 
expressão das relações reais do indivíduo com o meio. A educação pelo movimento, utilização e contribuição da ação, do movimento, para desenvolver, facilitar e reforçar a aprendizagem escolar, se bem integre a Educação Física, é um princípio universal reconhecido por médicos, psicólogos, educadores e especialistas.

Gesell (1977) reconhece a importância do movimento como elemento de construção da personalidade e do desenvolvimento motor da criança, resultado por um lado,das experiências vividas e por outro lado,da maturação fisiológica,quando afirma:

O crescimento é movimento. Nossa principal preocupação deve ser a posição da criança dentro de um ciclo dotado de movimento progressivo.

\section{Tipos de exercícios utilizados na Educação Física que auxiliam na aprendizagem}

Segundo Melcherts(1996)." As conceituações básicas, finalidades, objetivos gerais, princípios, características essências, necessidades bio-psico-fisiológicas da criança, conteúdos progmáticos e fundamentos básicos que devem ser considerados no processo ensinoaprendizagem da Educação Física em nível pré-escolar e escolar, são subsídios suficientes para desenvolver atividades dessa disciplina, desde que observadas as características e peculiaridades da clientela-alvo, bem como as condições de materiais existentes nas unidades escolares".

Essas atividades devem ser desenvolvidas sob forma de objetivos finais ou comportamentais, de acordo com os seguintes conteúdos, próprios de desenvolvimento psicomotor: Movimentos naturais, aptidões perceptivas, aptidões físicas, habilidades motoras, comunicação não verbal e higiene. Esses conteúdos são abordados de maneira sucinta para que o professor tenha uma visão clara da abrangência de cada um deles.

Os movimentos naturais são movimentos motores inatos pelos quais, através dos movimentos locomotores (andar, marchar, correr, saltar, saltitar e galopar), de trabalhos engenhosos (arremessar, lançar, rolar, chutar e quadrupedar) e de manipulação (segurar, pegar, transportar e movimentar); são atividades as potencialidades naturais da criança.

As aptidões perceptivas são as que auxiliam o aluno a interpretar o significado dos estímulos orais, visuais, táteis, auditivos, corporais e de coordenação, entre outros, tomando consciência do seu corpo, da forma pela qual ele se move, da sua posição no espaço e das relações entre ele e o meio ambiente. Praticamente, do estímulo adequado das atividades perceptivas depende a integração da criança ao seu meio, bem como o desenvolvimento de aptidões físicas que lhe permitirão executar habilidades motoras das mais simples às mais complexas.

As aptidões físicas são aquelas que caracterizam o funcionamento do vigor orgânico, através das qualidades físicas de resistência, força, flexibilidade, agilidade e velocidade. Já as habilidades motoras correspondem ao desenvolvimento de um grau de competência como resultado do ajustamento do corpo humano às solicitações de atividades naturais, perceptivas e físicas em fases anteriores de crescimento orgânico e psíquico da criança. Na maioria das vezes, essas solicitações manifestam-se sob a forma de habilidades, em jogos apropriados, dos mais fáceis para os mais difíceis.

A comunicação não verbal é meio que o ser humano utiliza para comunicar-se através de movimentos expressivos (postura, andar, gestos e expressão facial), interpretativos, estáticos e 
criativos, procurando representar fenômenos subjetivos de forma objetiva (o que seu corpo é capaz de executar no espaço, com graça, ritmo e movimentos criadores). A comunicação não verbal corresponde, na criança, a um estágio avançado do movimento, pois que, ao desenvolvimento bio-psico-físico-social ajustado, harmônico e sequenciado, há sempre uma resposta mais elaborada e precisa nas condutas manifestas da área cognitiva, afetiva e especialmente psicomotora.

A higiene é o meio de integrar a criança aos costumes, hábitos e normas que ajudam a preservar e a melhorar a saúde em geral. Estão sendo aqui abordados: higiene corporal, exercícios respiratórios e de relaxamento. Esses conteúdos correspondem às necessidades bio-psicofisiológicas e sociais da criança e devem ser desenvolvidas conforme as possibilidades que os meios da Educação Física (Ginástica geral e suas modalidades, jogos e recreação, atividades rítmicas, higiene) oferecem para a agilização do processo ensino-aprendizagem. Todavia, não se deve esquecer de que esse tipo de conteúdos, com suas divisões e subdivisões, obedecem às necessidades primárias da criança, de acordo com sua faixa etária, delimitando, assim aquilo que ela pode e deve desenvolver por meio de objetivos apropriados.

As habilidades motoras (habilidades adaptativas simples, compostas e complexas) em geral, correspondem a processos de coordenação motora mais elaborada, de acordo com esportes individuais e coletivos próprios da Educação Física.

As aptidões perceptivas desenvolvidas através da ginástica geral são: Discriminação entre o corpo e os objetos circundantes no espaço, além da lateralidade e do domínio esquerda-direita; Discriminação auditiva-acuidade auditiva e memória auditiva; Discriminação tátil e aptidões coordenadas-coordenação olhos-pés e óculo-manual.

Os movimentos naturais desenvolvidos através da Ginástica Natural são os movimentos locomotores, de trabalhos engenhosos e de manipulação.

Aptidões físicas através de ginástica formativa são atividades de: resistência-muscular e cardiovascular-força, flexibilidade e agilidade.

\section{Materiais e métodos ou Procedimentos Metodológicos}

Visando pesquisar sobre de que maneira é vista a importância da psicomotricidade no contexto de ensino-aprendizagem de alunos em idades escolares se fez necessário obter um instrumento de pesquisa ao qual avaliasse o que os professores de séries iniciais pensam deste importante processo.

Foram entrevistadas sete professoras de uma escola municipal de ensino fundamental de São Gabriel/RS desde a pré-escola até o quinto ano. As entrevistas abordaram o tema:"Apsicomotricidade: uma ferramenta de ajuda aos professores na aprendizagem escolar".

A escola que possui 453 alunos se situa no centro da cidade e possui nas séries iniciais 07 professores entre os turnos manhã e tarde a qual também possui sala de recursos para ajudar alunos que se encontram em dificuldades de aprendizagem por uma série de fatores.

A entrevista realizada com os professores da referida escola tem seus professores de séries inicias a grande maioria formados em Pedagogia, o que mostra a figura 3. 


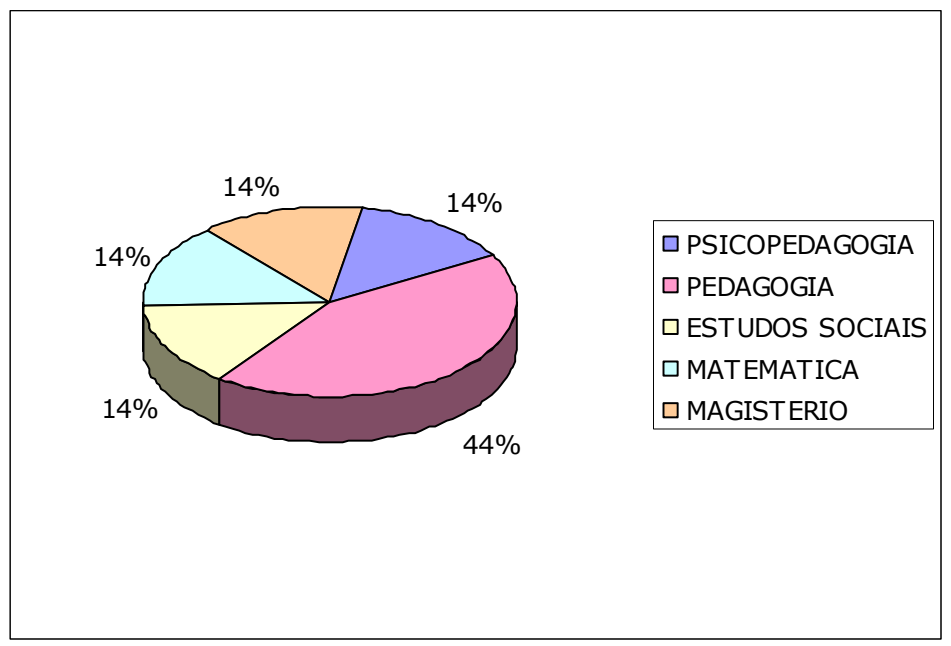

Figura 3:Formação dos professores

\section{RESULTADOS E DISCUSSÕES}

Sobre a pergunta se eles fazem cursos de aperfeiçoamento, dos sete professores entrevistados, quatro fazem cursos e especificaram quais e três professores não fazem cursos, nem mesmo os oferecidos pela Secretaria Municipal de Educação (SEME).

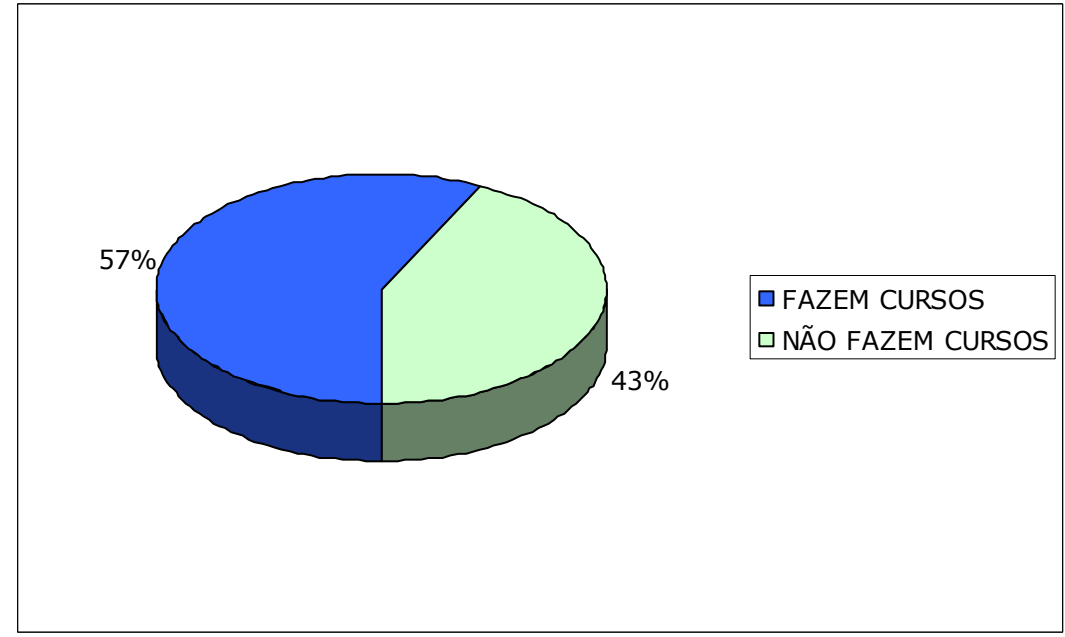

Figura 4:Cursos de aperfeiçoamento

$\mathrm{Na}$ pergunta direcionada aos entrevistados se praticavam Educação Física, quatro praticavam e três não praticavam. 


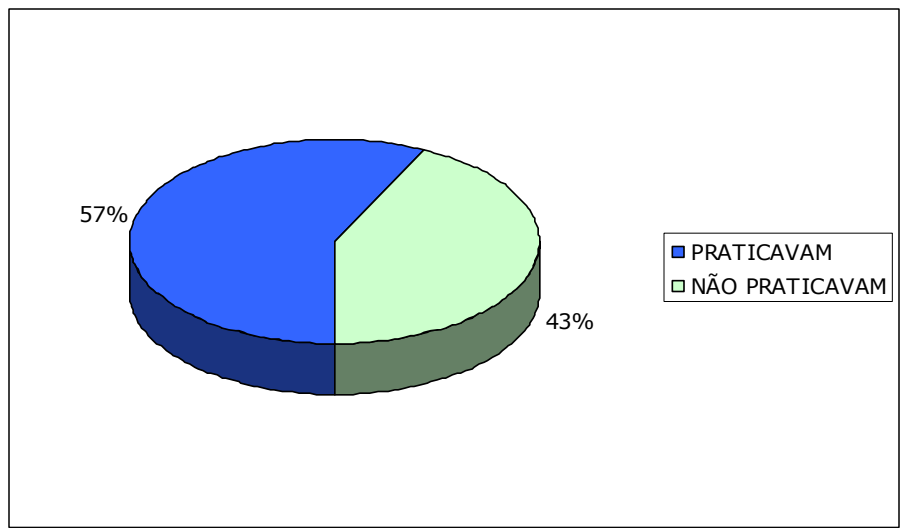

Figura 5: Professores que praticavam a Educação Física.

No que se refere sobre o conhecimento sobre a psicomotricidade, todos os professores assinalaram o conceito de que psicomotricidade é o termo empregado para uma concepção de movimento organizado e integrado, em função das experiências vividas pelo sujeito cuja ação é resultante de sua individualidade, sua linguagem, sua motricidade e sua socialização.

A pergunta sobre se todos educadores aplicam as atividades psicomotoras, todos afirmaram que aplicam figura 6 e quanto a percepção deles sobre a melhora no desempenho nas atividades, 6 assinalaram que sim e apenas um educador acredita que não há melhor desempenho na aprendizagem figura 7 .

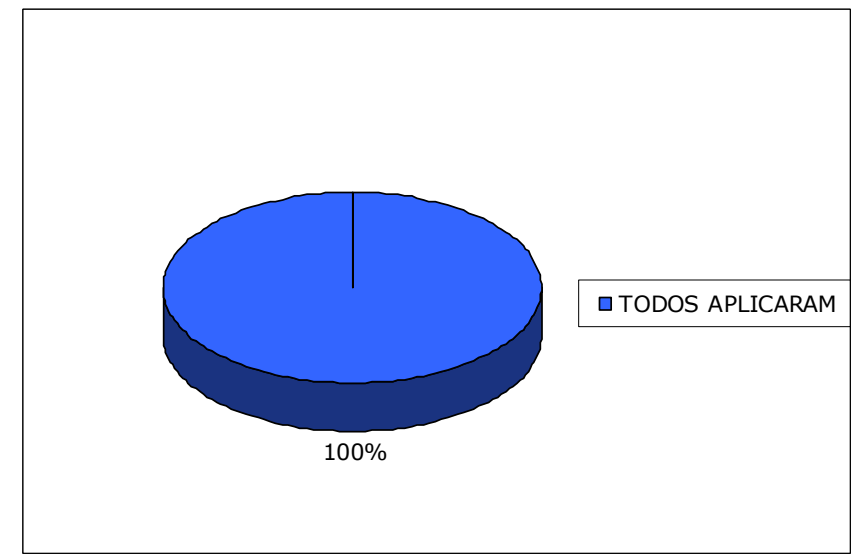

Figura 6: Aplicação da psicomotricidade nas aulas 


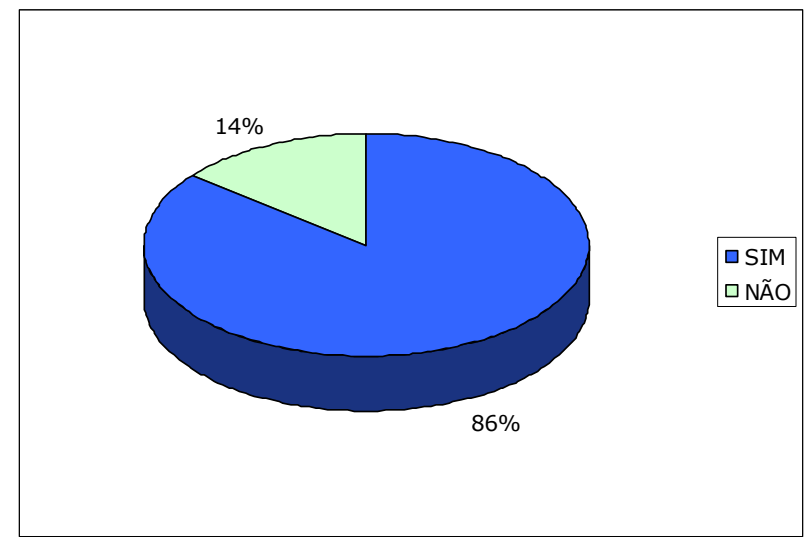

Figura 7: Desempenho na aprendizagem

Quando foi perguntado se as aulas ministradas sobre este tema são executadas em sala de aula, em quadra ou em ambas alternativas, todos marcaram a alternativa que é trabalhada a psicomotricidade em sala de aula e em quadra. Uma das entrevistadas salienta a importância da psicomotricidade no que tange a melhora na aprendizagem tanto nos exercícios cognitivos desenvolvidos em sala de aula quanto, atividades motoras que trabalham organização espaçotemporal, lateralidade, esquema corporal, coordenação e etc. em quadra.

E por último todos confirmaram que alunos com déficit de atenção, ao aplicar as atividades de psicomotricidade percebem uma melhor concentração destes nas atividades propostas.

\section{CONSIDERAÇÕES FINAIS}

Pode-se afirmar que a psicomotricidade possui impacto positivo no pensamento, no conhecimento e nos domínios cognitivos dos alunos.

De tal forma que os professores também constatam essa importância da utilização da psicomotricidade em suas aulas para desenvolver com mais facilidade a aprendizagem dos seus alunos.

Tem-se como objetivo final contribuir para a formação dos educandos através de domínios cognitivos, emocionais e psicomotores tornando-os pessoas autônomas e desenvolvidas.

\section{REFERÊNCIAS BIBLIOGRÁFICAS}

BARRETO, Sidirley de Jesús.Psicomotricidade,educação e reeducação.2 a.ed.

Blumenau: Livraria Acadêmica, 2000.

FONSECA, Vitor. Psicomotricidade. 2a . ed.São Paulo:Martins Fontes,1988.

OLIVEIRA, Gislene de Campos. Psicomotricidade:educação e reeducação num enfoque psicopedagógico.Petrópolis:Vozes,1997.

PIAGET, Jean. Seis estudos de psicologia. Rio de Janeiro: Editora Forense Universitária Ltda,1987. 
WALLON, Henri. As origens do caráter na criança. São Paulo: Difusão Européia do Livro, 1971.

WALLON, Henri. Do ato ao pensamento: ensaio de psicologia comparada. Lisboa:

Moraes Editores, 1979.

AJURIAGUERRA, J.de.Manual de psiquiatria infantil.Rio de Janeiro:Editora Masson do Brasil Ltda,1980.

MELCHERTS, Hurtado Johann Gustavo Guillermo. Educação Física pré-escolar e escolar: uma abordagem psicomotora. 5a. ed.Porto Alegre:Edita,1996.

GESELL, Arnold ET alli.El niño de 1 a 5 años.Buenos Aires:Pai-dos,1977.

SKINNER, B.F.Ciência e comportamento humano.São Paulo:Martins Fontes,1978.

SCOTT, K.Powers;HOWLEY,T.Edward.Fisiologia do exercício:teoria e aplicação ao condicionamento e ao desempenho.3a.ed.São Paulo:Editora Manole Ltda,2000.

WALLON, Henri; ALFANDÉRY, Hélène G. Educação-pensadores.Recife:Editora

Massangana, 2010.

MEUR, A; STAES, L.Psicomotricidade: educação e reeducação. São Paulo: Editora Manole Ltda, 1984.

SANTOS, R.C.F et al.Psicomotricidade:uma ferramenta norteadora no processo de ensinoaprendizagem de crianças com dislexia.Revista Ciência em Extensão,São Paulo,v.5,n.2,p.79,2009.

LE BOULCH, Jean. A Educação Psicomotora: a psicocinética na idade escolar. Porto Alegre: Artes Médicas, 1983. 